\title{
Successful Management of Hypotension Induced by Low Intracranial Pressure with Intravenous Administration of Lidocaine
}

\section{Zhi-Ming Zhang*, Bin Zeng and Fan OuYang}

Department of Anesthesiology, the Chenzhou No.1 People's Hospital, Institute of Translational Medicine, University of South China, Chenzhou, Hunan, 423000 , PR China

"Corresponding author: Zhi-Ming Zhang, Department of Anesthesiology, the Chenzhou No.1 People's Hospital, Luojiajin102, West Street, Beihu District, Chenzhou City, Hunan Province, 423000, PR China, Tel: +8613875555649; Fax: +8607352343205; E-mail: otc0735@163.com

Received Date: May 23, 2017; Accepted Date: June 29, 2017; Published Date: July 2, 2017

Copyright: (C) 2017 Zhang ZM, et al. This is an open-access article distributed under the terms of the Creative Commons Attribution License, which permits unrestricted use, distribution, and reproduction in any medium, provided the original author and source are credited.

\section{Abstract}

A man suffered severe hypotension down to $20 \sim 30 \mathrm{mmHg}$ when he received a surgical remove of glioma. This hypotension was hard to treat with many ways due to the blood pressure did not show any response to many vasoconstrictors, such as: adrenaline, norepinephrine, dopamine, and Aramine etc. A rapid injection of lidocaine 200 mg from right femoral vessel showed an efficient effect on promoting blood pressure when combined with other vasoconstrictors.

Keywords: Hypotension; Severe; Lidocaine; Intravenous; Low intracranial pressure

\section{Introduction}

Hypotention induced by leakage of cerebrospinal fluid was reported occasionally [1]. Small dose of leakage may be the potential cause of intracranial hypotension, and some treatments worked as patch on epidural were also reported [2-4]. Normally, the leakage of CBF was small and slow, and severe degrees of intracranial hypotension were related with the speed or the amount with CBF leakage [4]. A large amount of CBF leakage in a short time could be very dangerous to the patient, and it is hard to treat [5]. Here we reported our successful treatment about a severe hypotention induced by low intracranial pressure with lidocaine during the surgery.

\section{Case Report}

A 43-year-old male patient received surgical remove of glioma at the parietal lobe underwent the general anesthesia after being diagnosed. Preoperative examination revealed that the functions of the heart, lung and kidneys were normal. The patient was monitored by ECG, IBP, $\mathrm{SpO} 2, \mathrm{P}_{\mathrm{et}} \mathrm{Co} 2$; prior to the operation, continuous lumbar punctures were carried out, and an indwelling tube was secured in place to drain the cerebrospinal fluid, the purpose of which is to reduce the intracranial pressure for better exposure of the surgical field; after anesthetic induction, artificial airway was established, anesthesia was maintained with intravenous continuous infusion of Propofol, Remifentanil, and muscle relaxation with Atracuriun. The operation was begun half an hour later, and after the craniotomy and the opening of the dural mater, the blood pressure of the patient was found to drop drastically from $123 / 68 \mathrm{mmHg}$ to $54 / 32 \mathrm{mmHg}$ about $3 \mathrm{~min}$ after the skin incision was finished, and drop continuously later; the author ruled out the mechanic malfunction and enormous blood loss, and determined that it may be caused by the drainage of cerebrospinal fluid up to $140 \mathrm{~mL}$. Intravenous administration of Dopamine at the dosage of $6 \mathrm{mg}, 20 \mathrm{mg}$, and $20 \mathrm{mg}$ again cannot reverse the drop of the blood pressure, neither did the intervention with combined use of Aramine
(Metaraminol), Adrenaline, Norepinephrine and Dexamethasone. One hour after the drop of the blood pressure, the fluid we infused into the patient include $2500 \mathrm{~mL}$ colloid, $2000 \mathrm{~mL}$ crystalloid, and $4 \mathrm{U}$ red blood cells, in addition to $80 \mathrm{~mL}$ normal saline injected into the subarachnoid space. Despite all these efforts, the blood pressure of the patient was barely keep at 20 23/10 12 $\mathrm{mmHg}$, and heart rate hovering around $120 \mathrm{bpm}$, with oxygen saturation status unable to detect. The cardiovascular expert was invited into the operating room for consultation, whose advice were tried but still with futile efforts to bring up the blood pressure. In consideration of the urgent situation, the author suggested the remedy of intravenous infusion of large dose of Lidocaine, after obtaining the approval of the ethic committee of the hospital, $200 \mathrm{mg}$ of Lidocaine was rapidly injected through the femoral vessel; in the initial $2 \mathrm{~min}$ after the injection, no obvious change of blood pressure was detected; 3 min after the injection, the monitoring screen demonstrated the slow rise of the blood pressure, returning from $22 / 12 \mathrm{mmHg}$ to $35 / 18 \mathrm{mmHg}, 104 / 65 \mathrm{mmHg}, 146 / 75 \mathrm{mmHg}$ at 5 $\mathrm{min}, 10 \mathrm{~min}$ and $15 \mathrm{~min}$, respectively. Then, a norepinephrine was i.v. injected continually at $1.6 \mathrm{mg} / \mathrm{h}$ to maintain the blood pressure of the patient at $130 / 70 \mathrm{mmHg}$ and escort him back to the intensive care unit for further treatments and observations. Unfortunately, this patient was diagnosis as (Multiple Organ Failure) MODS in Intensive care unit (ICU) at the next day: Acute Renal Failure (ARF), with Blood Urea Nitrogen (BUN) up to $51.4 \mathrm{mmol} / \mathrm{L}$ and Creatinine up to $632 \mu \mathrm{mol} / \mathrm{L}$. Acute Respiratory Distress Syndrome (ARDS), with $\mathrm{PaCO} 2$ up to 96 $\mathrm{mmHg}, \mathrm{PaO} 2$ down to $36 \mathrm{mmHg}$, and died 4 days later.

\section{Discussion}

Lidocaine is the commonly used local anesthetics, which is often adopted in local anesthesia [6], intravenous regional anesthesia [7], and epidural anesthesia [8,9]; meanwhile, it is also used as an antiarrhythmic drug to treat ventricular arrhythmia [10]. Due to its excellent efficacy of surface anesthesia, it has been reported to be used to attenuate the injection pain caused by Propofol and Etomidate with good results $[11,12]$; it also has been used to prevent the endotracheal suctioning-induced cardiovascular reactions through endotracheal instillation [13]; other reports suggested that Lidocaine by intrathecal 
injection can relieve the vasoparesis caused by acute neurogenic hypotension and the occurrence of myocardial dysfunction [14]. Sharp drop of blood pressure often occurs in acute brain trauma managed by craniotomic decompression, especially when the dural mater is breached, possibly related to Cushing reaction [15]. In our reported case, after the opening of the dural mater and drainage of large amounts of cerebrospinal fluid, the intracranial pressure dropped sharply, followed by reactive drastic decline of blood pressure, which cannot be addressed by fluid infusion of large volume and injection of various vasoactive drugs, possibly attributable to sympathetic paralysis. When we took consideration of that Lidocaine can attenuate the vasoparesis induced by neurogenic hypotension and that it is one of the local anesthetics which can be used intravenously and is with effect of surface anesthesia, we gave the patient rapid injection of $200 \mathrm{mg}$ of lidocaine, achieving obvious effects and winning a second operative chance for the patient. In review of what happened in our case and what has been reported in literature, we hypothesize that the phenomenon in our case is related to the surface anesthesia by lidocaine: after rapid injection of lidocaine, anesthesia of the internal vascular wall can reduce the intensity or totally block Cushing reaction, bring back the blood pressure. However, since it is still less known about target sites in the reflex arc of Cushing reaction, the exact mechanism of the effect of intravenous injection of lidocaine on Cushing reaction still waits for further study.

\section{References}

1. Schievink WI, Maya MM, Chu RM, Moser FG (2015) False localizing sign of cervico-thoracic CSF leak in spontaneous intracranial hypotension. Neurology 84: 2445-2448.

2. Gulur P, Buonanno FS (2013) Intracranial hypotension caused by anterior cervical CSF leak alleviated by an epidural blood patch [corrected]. Headache 53: 838-841.

3. Inamasu J, Nakatsukasa M (2007) Blood patch for spontaneous intracranial hypotension caused by cerebrospinal fluid leak at C1-2. Clin Neurol Neurosurg 109: 716-719.

4. Wang E, Wang D (2015) Successful treatment of spontaneous intracranial hypotension due to prominent cervical cerebrospinal fluid leak with cervical epidural blood patch. Pain Med 16: 1013-1018.
5. Sykes KT, Yi X (2013) Intracranial hypotension headache caused by a massive cerebrospinal fluid leak successfully treated with a targeted c2 epidural blood patch: a case report. Pain Physician 16: 399-404.

6. Morganroth PA, Gelfand JM, Jambusaria A, Margolis DJ, Miller CJ (2009) A randomized, double-blind comparison of the total dose of $1.0 \%$ lidocaine with 1:100,000 epinephrine versus $0.5 \%$ lidocaine with 1:200,000 epinephrine required for effective local anesthesia during Mohs micrographic surgery for skin cancers. J Am Acad Dermatol 60: 444-452.

7. Viscomi CM, Friend A, Parker C, Murphy T, Yarnell M (2009) Ketamine as an adjuvant in lidocaine intravenous regional anesthesia: a randomized, double-blind, systemic control trial. Reg Anesth Pain Med 34: 130-133.

8. Asik I, Kocum AI, Goktug A, Turhan KS, Alkis N (2009) Comparison of ropivacaine $0.2 \%$ and $0.25 \%$ with lidocaine $0.5 \%$ for intravenous regional anesthesia. J Clin Anesth 21: 401-407.

9. Chen YW, Chu CC, Chen YC, Wang JJ, Hung CH (2010) Isobolographic analysis of caramiphen and lidocaine on spinal anesthesia in rats. Neurosci Lett 469: 174-178.

10. Purali N, Yagcioglu S (2002) Lidocaine diminishes arrhythmia by Leiurus quinquestriatus quinquestriatus venom in rats. Fundam Clin Pharmacol 16: 227-235.

11. Nyman Y, Von Hofsten K, Palm C, Eksborg S, Lönnqvist PA (2006) Etomidate-Lipuro is associated with considerably less injection pain in children compared with propofol with added lidocaine. Br J Anaesth 97: 536-539.

12. Brock MF, Grace BE, Morley B, Hillegass G, Houle TT, et al. (2010) Does lidocaine more effectively prevent pain upon induction with propofol or etomidate when given preemptively than when mixed with the drug? J Clin Anesth 22: 505-509.

13. Bilotta F, Branca G, Lam A, Cuzzone V, Doronzio A, et al. (2008) Endotracheal lidocaine in preventing endotracheal suctioning-induced changes in cerebral hemodynamics in patients with severe head trauma. Neurocrit Care 8: 241-246.

14. Hall SR, Wang L, Milne B, Ford S, Hong M (2002) Intrathecal lidocaine prevents cardiovascular collapse and neurogenic pulmonary edema in a rat model of acute intracranial hypertension. Anesth Analg 94: 948-953.

15. Miller P, Mack CD, Sammer M, Rozet I, Lee LA, et al. (2006) The incidence and risk factors for hypotension during emergent decompressive craniotomy in children with traumatic brain injury. Anesth Analg 103: 869-875. 